\title{
Humor in the elderly with dementia: Development and initial validation of a behavioral observation system
}

\author{
Gudrun Baumgartner ${ }^{1}$ (D) $\cdot$ Karl-Heinz Renner ${ }^{2}$
}

(C) The Author(s) 2019

\begin{abstract}
Interventions with Clinic Clowns trained for performing in nursing homes have been explored in several field studies. Until now, however, it has not been sufficiently investigated to which extent and in which ways elderly with dementia (EWD) respond to and engage in humorous interactions. An exploratory study with 17 German dementia care unit residents aimed at narrowing this gap. To assess understanding, appreciation and authorship as well as contextual information we have constructed a behavioral observation and annotation system for humor interaction with the elderly with dementia (ANHIDE) The system was tested for inter-coder agreement and reached kappa values qualified as substantial for humor categories $(\kappa=.685)$, humor response $(\kappa=.725)$ and musical contributions ( $K=.752)$. In 9 hours of video recorded interaction, participants contributed almost a third of the annotated humor events with verbal humor being their most frequent way of expression. Benign humor styles prevailed $(85 \%)$ and aggressive humor was rare $(2 \%)$. Whenever participants could be addressed successfully, they responded overly positive $(89 \%)$. Malign humor styles were - if not ignored - answered with disapproval or the attempt to reconcile. Best practice recommendations for addressing and involving the residents with dementia are well-structured contributions and combined use of various stylistic means. Limitations, as well as suggestions for further in-depth research, are discussed, e.g., individual differences in humor response, strategies to encourage participants' active contribution or fostering humor as a behavioral competence. Overall, this contribution is the first to provide a behavioral observation system for a detailed annotation of humor interactions regarding the elderly with dementia (ANHIDE). We demonstrate preliminary evidence for competencies in humor perception and production in the target group.
\end{abstract}

Keywords Humor intervention $\cdot$ Humor interaction $\cdot$ Behavioral observation system $\cdot$ Dementia $\cdot$ Positive psychology

\section{Introduction}

Clown visits have become an established psychosocial intervention (Linge-Dahl et al. 2018) for nursing home residents with dementia. Apart from entertaining and cheering up, extant studies usually focus on improvements in patients' behavior or quality of life and aim at reducing challenging behaviors like apathy, delusions, agitation, and aggression or aberrant

Gudrun Baumgartner

gudrun.baumgartner@gmail.com

Karl-Heinz Renner

karl-heinz.renner@unibw.de

FernUniversität in Hagen, Hagen, Germany

2 Universität der Bundeswehr München, Neubiberg, Germany motor behavior (e.g., Garms-Homolová and Kiki 2003; Low et al. 2013). Changes can be assessed by validated staffadministered questionnaires, e.g., the Neuropsychiatric Inventory, Nursing Home Version (NPI-NH, Cummings 2009) and the Quality of Life in dementia (QUALIDEM, Ettema et al. 2007) that are widely used for various kinds of psychosocial interventions (Dichter et al. 2014a, b). In this output-oriented research, details, and dynamics of the intervention regularly remain undocumented.

A sole focus on the output limits our understanding and does not tell us anything about intervention-specific mechanisms that remain unobserved and hence mostly unknown. Apart from a wide range of anecdotal evidence (Hawkins and Graff-Radford 2007; Bischofberger 2007), this is also true for humor interventions for the elderly with dementia (EWD). Researchers taking field notes or recording interactions during such interventions, emphasize the importance of a friendly, empathetic, playful and soft encounter (Dunn et al. 2013), highlight the "reciprocal nature of Clown-resident 
engagement" (Kontos et al. 2015) and assume that "active participation by people with dementia (PWD) in performing to create laughter is more beneficial therapeutically than passively induced laughter" (Stevens 2012). Several studies have also focused on conversational humor and its functions in general (e.g., Hay 2001; Gironzetti et al. 2016).

Although understanding and treatment of dementia have undergone a notable paradigmatic shift from concentrating on patients' shortcomings towards resource-oriented approaches, process-oriented research is scarce. Thus, careful behavioral observation and analysis of the performance and interactions between Clinic Clowns and residents are crucial to better understand the mechanisms that lead to desired outcomes, besides to solely relying on the results from staffadministered questionnaires. To the best of our knowledge, no behavioral observation system to address this research question is available as yet. Therefore, we aimed at two main research questions:

(1) Our first objective was the development of such an observation and annotation system for humor interaction with elderly persons with dementia (ANHIDE).

(2) The second main objective was a first application and validation of the ANHIDE. In doing so, the potential of humorous and playful interaction with EWD was explored. In particular and based on extant research in the fields of positive psychology (especially humor), dementia and geronto-psychiatry, the following research questions were explored in the initial validation process:

\section{Humor Reception, Understanding, and Participation: Are EWD Able to Perceive, Appreciate, and Produce Humor?}

The ability to understand and produce humor seems to be "a genetic component of human biology, and probably has been elaborating along with other human behavior for a very long time "(Fry 1994, p. 120). The sense of humor $(\mathrm{SOH})$ remains stable across age groups (Proyer et al. 2010), although ways and functions of humor vary with age (Falkenberg 2010). SOH is positively associated with well-being and remains a "character strength among the elderly "(Ruch et al. 2010). Even in patients with severe dementia, the capacities for experiencing and expressing humor still seem to be preserved (Bär, Kruse \& Re 2003; Re 2003; Kruse 2005). The ability to perceive, appreciate and produce humor might be observable throughout all stages of the disease (Falkenberg 2010), and persons with dementia even seem capable to use their sense of humor as a strategic means in communication (Dooley et al. 2015). Based on these findings, we aimed at exploring whether EWD would readily pick up offers to participate, respond, and actively contribute to a humorous interaction with Clinic Clowns. The extant studies that attest humor skills to EWD, however, suffer from severe methodological shortcomings: The number of participants is small (< 10) and only unsystematic, informal observation without video recordings was applied. As a consequence, results and conclusions are only based on anecdotal evidence. Furthermore, humor production skills are widely neglected, and individual differences are not considered. The success of humor interventions is usually measured by questionnaires, often focussing on "improved" behavior. Thus, we aimed at exploring whether EWD would readily pick up offers to participate, respond and actively contribute in a humorous interaction with Clinic Clowns based on a more rigorous methodology, i.e., by systematically and carefully observing the videotaped interactions with the ANHIDE.

\section{Positive Emotions: Do Humorous Interactions Between EWD and Clinic Clowns Lead to Observable Changes in Mood, Atmosphere, and Positive Emotions?}

Humorous and playful interactions might be emotionally relevant favorable breaks and resources in an otherwise dull nursing home routine. Bär et al. (2003, 2006) have demonstrated the importance of addressing situations of emotional significance in persons with dementia. Humorous interactions might prove to be such situations and lead to changes in mood, atmosphere, engagement, and positive emotions. Therefore, it should be possible to observe and register such changes with the ANHIDE.

\section{Method}

\section{Sample and Setting}

The ANHIDE was part of a larger research project described in Baumgartner (2016). Participants for the behavioral observation study were 17 German nursing home residents with dementia. For all participants, a declaration of consent was signed by their legal guardians. The participants were visited by two and the same professional Clinic Clowns twice a week for 4 weeks. Professional Clinic Clowns undergo continuous, specific training to meet the needs of their target group (e.g., persons with dementia). The Clowns employed in this study were professionals of the Kölner Klinik Clowns e.V., an organization that is also a certified member of the German Clowning Confederation (Dachverband Clowns in Medizin und Pflege Deutschland e.V. $)^{1}$

\footnotetext{
${ }^{1}$ For further information see https://www.dachverband-clowns.de/
} 
The eight intervention sessions were completely video recorded and resulted in 9 hours of video material.

The video recording was carried out as a non-participating observation in the participants' natural environment. The camera operator was either known to the residents from previous recordings or was introduced by the Clowns during the intervention. It can be assumed that the presence of the camera operator went mostly unnoticed and the residents seemed unaware that they were filmed. This effect of "invisibility by visibility" is also known from other studies (Krappmann and Oswald 1995). Random interaction and sporadic perception of the camera operator does not affect the observable behavior (Krappmann and Oswald 1995). Furthermore, the camera was usually mounted on a tripod and ran for long stretches without manual operation.

The 17 residents scored from 0 to $22(\mathrm{M}=11.4 ; \mathrm{SD}=8.3)$ in the Mini Mental State Test (MMST, Folstein et al. 2000) which is a short and practical test for assessing the cognitive state of patients. According to the test results, our participants were assigned in approximately equal parts into the classes of mild $(n=5)$, moderate $(n=6)$ and severe $(n=6)$ dementia. They were aged from 69 to $99(\mathrm{M}=86.3 ; \mathrm{SD}=7.3)$ and 16 (94\%) of them were female. Participants met with the Clowns either in a lounge area where they sat at their accustomed dining tables or were visited in their private rooms.

\section{Video Annotation}

The Clinic Clown intervention was recorded with a Panasonic HC X909 Camcorder. The videos were annotated with the freeware tool ANVILC (version 5.1.12; http:// www.anvil-software.org, Michael Kipp, 2000-2013). After cutting scenes showing dropped-out residents or persons who did not participate, 9 hours of video material remained. As documentation on humor interaction is rare, we decided on annotating the full 9 hours. In this study, participation and musical contributions, as well as take and atmosphere, were annotated as states. Authorship and humor response were registered as events. Humor contributions and topics, although annotated with a duration, were regarded as events only. To allow for the registration of additional observations, captions of scarcely audible comments or disruptions and consequences, auxiliary annotation tracks were provided for unrestricted use.

Figure 1 shows a sample annotation scene. The vertical line marks the time of the snapshot. The lady to the left is just about to start telling a joke (annotated as affiliative pun and authorship. Her tablemate will stay unimpressed by the humorous contribution (no response). The Clowns will answer the pun with a slapstick interpretation, making the author smile. Her neighbor, again, will stay unimpressed (no_response).

\section{Findings}

As the ANHIDE was developed as part of an actual field study, this study was also the first in which it was applied to register humorous interactions regarding EWD. In the following paragraphs, we first describe the ANHIDE and also report on the Inter-Coder Agreement (Description of the ANHIDE section). The second part of the results section (Inter-Coder Agreement) pertains to preliminary results on the frequencies of humor perception and production by the participants as well as instances of perceived competence and failed humor or adverse effects. In reporting these results, we provide preliminary answers to our particular research questions that were formulated in the introduction.

\section{Description of the ANHIDE}

The ANHIDE was developed following Fassnacht's (1995) methodological approach for the construction of observation systems. In doing so, we mainly applied a bottom-up iterative process in which the 9 hours of videotaped humorous interactions were analyzed regarding the constructs (i.e., humor competencies and changes in mood, atmosphere, and emotions) that were addressed in our two research questions. ${ }^{2}$ The final version of the ANHIDE is structured as follows.

In the ANHIDE, Clowns and participants were either classified as individuals, dyads or (interacting) groups, and represented items on level 1 according to Fassnacht's model of cascading predication for the generation of units. The behaviors to be observed (level 2) may be chosen by the researcher, depending on his or her focus of interest. For this study, relevant behaviors were humorous events, humor reception, and participation in terms of audience as well as performance. Humor events were differentiated into humor techniques (e.g., verbal humor, slapstick, funny gadgets) and humor styles (affiliative, self-enhancing, self-deprecating, aggressive) as described by Martin (2003). On level 3, a range of behavioral indicators was defined in order to quantify the observed units. An example might illustrate our coding:

(1) Clown A (level 1) contributes a humor event (level 2) by telling a nonsense joke (registered as pun / affiliative, level 3).

(2) For Mrs. B (level 1) who is part of the audience, a response is registered (level 2): she seems to like the joke because she is smiling (level 3).

(3) $M r . C$ (level 1), also part of the audience, moves his head towards Clown A. He seems aware of something going

\footnotetext{
${ }^{2}$ A detailed description and explication of these categories are available from the first author upon request. Although the study was carried out in a German nursing home, the ANHIDE categories and manual were set up in English to facilitate further adaptation/validation.
} 


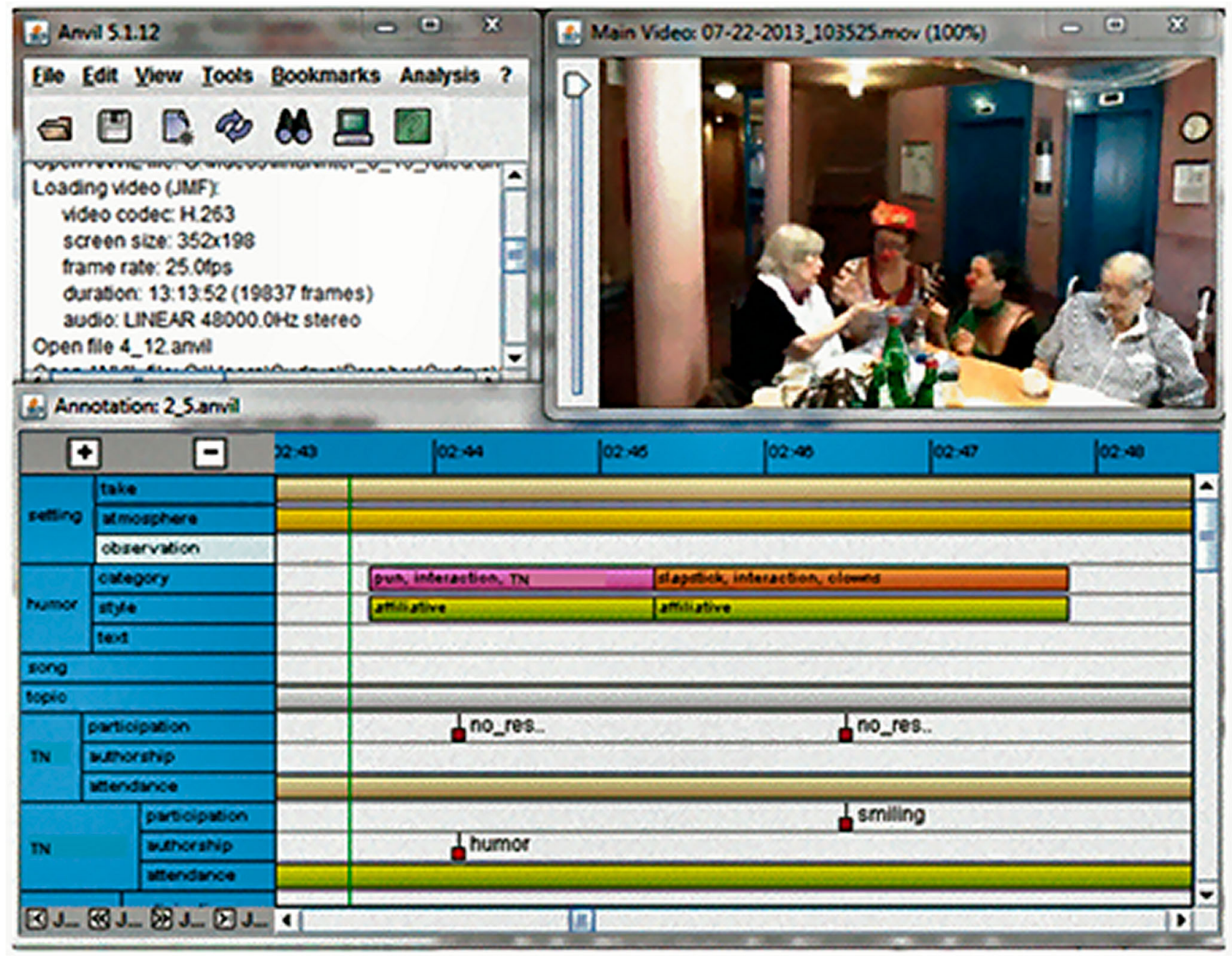

Fig. 1 Annotation with ANVILC

on, but neither understanding nor liking or disliking is expressed. His response (level 2) is registered as acknowledgement (level 3).

Level 4 requires a time value. This value may be a timestamp, a duration, or both. While a song will have a definite beginning and end, it is difficult to specify the distinct duration of observed behavioral items in an ongoing interaction. Therefore, humorous contributions were registered with an approximate duration but classified as single events. This approach seemed to be reasonable, as, e.g., the funniness or success of a joke is not related to its length.

In addition to observing and registering humor events and responses, we also registered situational information like setting, atmosphere, conversational topics, and field notes. The following broad observational categories were differentiated in an iterative process:

- Humor contribution

- Resident participation
- Relevant topic

- Setting

- Other (e.g., musical contribution, relevant topics, competencies, incidents, disturbance)

Whereas the main categories were pretty clear from the start by the behavior we wanted to register, subcategories had to be altered, extended, or dismissed. Furthermore, as literature in humor observation is scarce, we decided to set out with two models that are operationalized by self-report questionnaires regarding (1) humor appreciation (3WD humor test, Ruch 1983) and (2) humor styles (Martin et al. 2003). Since the three dimensions of the 3WD (Nonsense, Incongruity Resolution, and Sexual) were developed for the appreciation of puns or cartoons, they turned out to be mostly inapplicable in our interactional context and for our specific target group. After repeatedly reviewing the videos, the two structural categories incongruity resolution and nonsense proved difficult to differentiate, and the mere structure seemed not informative enough. Only the contextual category sexual 
was kept and other subcategories to assess the observed variety of humor productions were found. Similarly, the dimensions of the humor styles questionnaire (affiliative, self-enhancing, aggressive, and self-defeating) developed by Martin et al. (2003) had to be supplemented by a subcategory accidental for the registration of humor events that were produced unintentionally.

Our focus was mainly on the authorship of the participants, i.e., the Clowns and the EWD (to our knowledge an overseen topic as yet) and humor reception in general, reflected in humor responses and observable likings or dislikings, e.g., towards particular forms of humor. For the annotation of authorship, we differentiated between Clowns and individual participants only, although there indeed might be individual differences in the performance of the Clowns. Idiosyncratic effects of the individual Clowns' humor can, therefore, not be traced back.

Table 1 gives an overview of the main categories and subcategories that are described in the following sections (see also sample annotation shown in Fig. 1).

Environmental conditions like setting, prevailing moods, conversational issues, and musical contributions were registered in order to support the understanding and interpretation of the selected scenes (Baumgartner 2016). Because of this merely supporting function, predicator values, initially chosen by the first author's appraisal while repeatedly viewing the entire material, underwent only minor refinement.

\section{Humor Contributions}

As certain verbal and non-verbal patterns emerged, the subcategories pun, slapstick (e.g., exaggerated movement), grimace, funny noise, funny gadgets, gesture, make believe (e.g., short role plays), song, sex, and laughter were derived to register humorous contributions. This was also done bottom-up in an iterative process and led to denoting and explicating the different subcategories. Criteria for registration were either an observable attempt of the author to be funny (not necessarily successfully) or an observable reaction of the audience. For contributions that seemed not meant to be funny, the category accidental was added. Invisible or inaudible funny contributions (somebody laughing for an unobservable reason) were rated unknown.

\section{Humor Style}

Martin et al. (2003) introduced four humor styles in order to assess individual differences in humor use. These are two benign uses of humor, applied to foster relationships with others (affiliative) or to enhance the self (self-enhancing) and two malign uses of humor, intended to have fun at the expense of others (aggressive) or enhancing relationships at the expense of oneself (self-defeating). We assigned one of these four styles to each registered humor contribution. An additional category accidental was introduced as occasional Clowns and participants were funny without purpose.

\section{Humor Response}

For each annotated humor contribution, the corresponding response and authorship were registered as events. One (significant) response per visible participant was registered. As a positive reception seems crucial for successful humorous interaction (Kuiper et al. 2010) and a person's self-concept partly depends on how others see the person (Coulter 1979; Harré 1991), Clowns' responses to residents' humor contributions were also registered. Response meant any possible feedback related to the contribution and hence comprised various types of lacking or sparse reaction as well as the expression of appreciation, and negative or ambivalent reactions. Response
Table 1 Main categories and subcategories

\begin{tabular}{ll}
\hline Main categories/predicators & Subcategories/indicators \\
\hline Setting & Take, atmosphere, additional observations \\
Humor contribution & Pun, slapstick, grimace, funny noise, funny gadget, gesture, \\
& make believe (e.g., short role plays), song, sex, laughter, accidental \\
Humor style & Affiliative, self-enhancing, aggressive, self-defeating, accidental \\
Humor response & Sleeping, no_response, acknowledgement, shyness, ambivalence, \\
& disconcertment, aversion, liking, smiling, laughter, enthusiasm, \\
& picking_up, volitional laughter \\
Attendance & Group, neighbor, individual, atmospheric attendance \\
Atmosphere & Sleeping, indifferent, anticipation, conversational, positive, playful, \\
& cheerful, hilarious, sad, gloomy, depressive, aggressive, suffering \\
Musical contributions & Funny, cheerful, sentimental, melancholic, lullaby, memoirs, neutral \\
Topics and Competencies & Social skills, health, autonomy, appearance, creativity, \\
& daily activities, knowledge, and wisdom \\
\hline
\end{tabular}


values were sleeping, no_response, acknowledgement (line of gaze and/or body language suggest the registration of an action or humor event), shyness (participant acknowledges the humorous interaction but does not dare to participate or acts coyly), ambivalence (participant seemingly cannot decide whether to approve or disapprove), disconcertment (participant seems puzzled and not knowing what to make of the contribution), aversion (participant does not approve of the humor presented, e.g., Clown walking across the dining table), liking (if not smiling or laughing yet), smiling, laughter, and enthusiasm. For situations where residents or Clowns showed none of those reactions but maintained the flow of humorous interaction by contributing themselves, picking_up could be assigned. When a faked laughter was suspected, volitional laughter was annotated.

\section{Attendance}

The duration of residents' physical attendance was annotated in two ways: 1 . If residents were addressed individually, as members of a group setting, or if they could quickly join an ongoing interaction as a tablemate, the duration of this direct attendance was attested (group, neighbor, individual). 2. As a cheerful atmosphere also might contribute to a positive output, other seating arrangements were registered as well. If residents were seated at a neighboring table (up to a distance of three meters) or in the background, we assumed they could sense the prevailing mood (atmospheric attendance).

\section{Atmosphere}

Concerning the setting, take, and atmosphere were annotated for the length of their duration. As the take would usually be identical with the actual play scene, this information was meant to help quantify the proportion/percentage of different settings in the overall intervention (if needed). The prevailing mood (atmosphere) of the scenes was registered to detect favorable preconditions for humorous contributions (Ruch and Köhler 2007; Thaler et al. 2012). Indicators were sleeping, indifferent, anticipation, conversational, positive, playful, cheerful, hilarious, sad, gloomy, depressive, aggressive, and suffering.

\section{Musical Contributions}

Music is an integral and time-intensive part of most clowning performances. Songs were registered on a separate track with title and duration. Additionally, the prevailing mood of the musical contribution was annotated, because this mood might influence humor participation or overall mood. Possible values were funny, cheerful, sentimental, melancholic, lullaby, memoirs (e.g., national anthems) and neutral.

\section{Topics and Competencies}

During several nursing home visits whilst preparing for this study, residents repeatedly came up with obviously personally important topics they wanted to discuss or on which they wanted to give advice or express inability. These topics were registered in a correspondent category referring to social skills, health, autonomy, appearance, creativity, daily activities, knowledge, and wisdom as predicator values. Topics could be annotated as either expressing a competency or an inability. A further track served for registering events like applause, praise or thanks as well as observed distractions or disturbances and resulting consequences.

\section{Inter-Coder Agreement}

The inter-coder agreement was based on ten randomly selected sequences from the video material. These sequences comprised $60 \mathrm{~min}$ ( $11 \%$ of the overall recorded intervention time). As the analysis of the humorous interactions was the main interest of the study, only humor events (categories/techniques and styles), humor responses and musical contributions were considered for inter-coder agreement.

Humor Event Categories In total, 115 humor events were observed by the first author and an additional coder. Out of those, 91 were annotated by both coders. Twenty six of the 115 humor events were attributed to the residents $(23 \%$; coder agreement $85 \%$ ). For the given categories, Kappa was $\mathrm{K}=.685,95 \% \mathrm{CI}(0.579,0.791)$.

Humor Response For each scene, the responses of all visible (or audible) participants were annotated. Due to group settings, the number of observed responses was higher than the number of humor events. Actions and responses that seemed related to other activities were not registered. To facilitate the registration, only one single, namely the most salient response per participant and scene was annotated (e.g., if a resident would smile and laugh, only laughter was annotated). One hundred nine out of 134 annotated humor responses were observed by both raters $(=81 \%)$. For the given response categories Kappa was $\mathrm{K}=.725,95 \%$ CI $(0.635,0.815)$.

Best agreements were achieved for laughter and no_response, possibly because these responses could be delimited easily. As they were also the most frequent responses, they contributed to a good inter-coder agreement.

Musical Contributions For musical contributions, the prevailing mood and duration were registered. All of the 83 musical contributions were annotated by both coders (100\%). For the given mood values Kappa was $K=.752,95 \%$ CI $(0.639$, $0.866)$. As expected, a majority of the contributions were annotated as cheerful or funny. 


\section{Preliminary Results Regarding the Application and Validation of the ANHIDE}

In the following paragraphs, we report preliminary results regarding the application and validation of the ANHIDE. In doing so, we demonstrate that humor competencies, i.e., perceiving, appreciating, and producing humor, in EWD as well as changes in mood, atmosphere, and positive emotions during the interactions between Clinic Clowns and EWD are observable using the ANHIDE. We organize this section according to the two research questions that were formulated in the introduction.

\section{Are EWD Able to Perceive, Appreciate, and Produce Humor?}

As a prerequisite for the possibility to perceive, appreciate, and produce humor, attendance was observed in two ways, as direct attendance and atmospheric attendance (see Humor Style section). Since $86 \%$ of the intervention took place in the lounge and dining hall, we assumed that a majority of the participants could sense a change of atmosphere, even if they were not involved in the interaction. Figure 2 shows the respective durations of direct and atmospheric participation. Although the Clowns tried to devote their time equally to participants, direct participation varied from $0: 42$ to $2: 40 \mathrm{~h}$ $(\mathrm{M}=1: 51 \mathrm{~h} ; \mathrm{SD}=0: 30 \mathrm{~h})$. Participants who spent most of their day in their allotted seats in the lounge area were most likely to participate directly or sense a change of atmosphere. For participants who spent most of their time in their rooms, e.g., participants 21,22 , participation logically was very low.

Humor Production Out of 633 annotated humor contributions, $175(28 \%)$ were generated by the residents. Verbal humor was used most frequently by the Clowns as well as by the participants $(38 \%)$, followed by nonverbal humor forms such as slapstick (26\%), as-if games (14\%) and funny accessories (14\%). Usage by author is shown in Table 2.

Affiliative humor was used predominantly by Clowns as well as by participants $(89 \% / 75 \%)$. Self-enhancing humor accounted for $1 \% / 10 \%$ of the humor events, and selfdeprecating humor was annotated for $2 \%$ of both Clowns' and participants' contributions. Aggressive humor was also rare $(5 \% / 7 \%)$ and using aggressive humor was observed only in two participants. When employed by the Clowns, aggressive contributions were either ignored by the audience or negotiated for settlement. When, e.g., one Clown joked about the other's unbecoming costume (making her look fat), a resident commented that both Clowns were beautiful in their way. An additional $3 \% / 6 \%$ of the observed humor contributions occurred unintentionally.

Humor Response One thousand six hundred seventy-nine responses were annotated (1348 responses of residents and 331 responses of Clowns). Residents' responses are shown in Fig. 3.

Whenever residents could be reached, humor contributions were mostly appraised positively (89\%) and greeted with laughter, smiling, or other ways of expressing their liking. As shown in Fig. 3, almost half of the audience, however, did not seem to perceive a humor event and stayed indifferent when the video recording showed they could have noticed it. We observed this mainly in group settings where attracting attention is more difficult than in individual interactions, e.g., in a resident's private room.

Participation and response showed great individual differences in both reception and authorship (Fig. 4). As Fig. 4 shows, some participants still were in good command of verbal expression, e.g., participants 3, 14, 17, 22, 23, and 26 . These participants lived with mild or moderate dementia only. Some of these participants also readily engaged in as-if-games
Fig. 2 Direct and atmospheric participation by residents

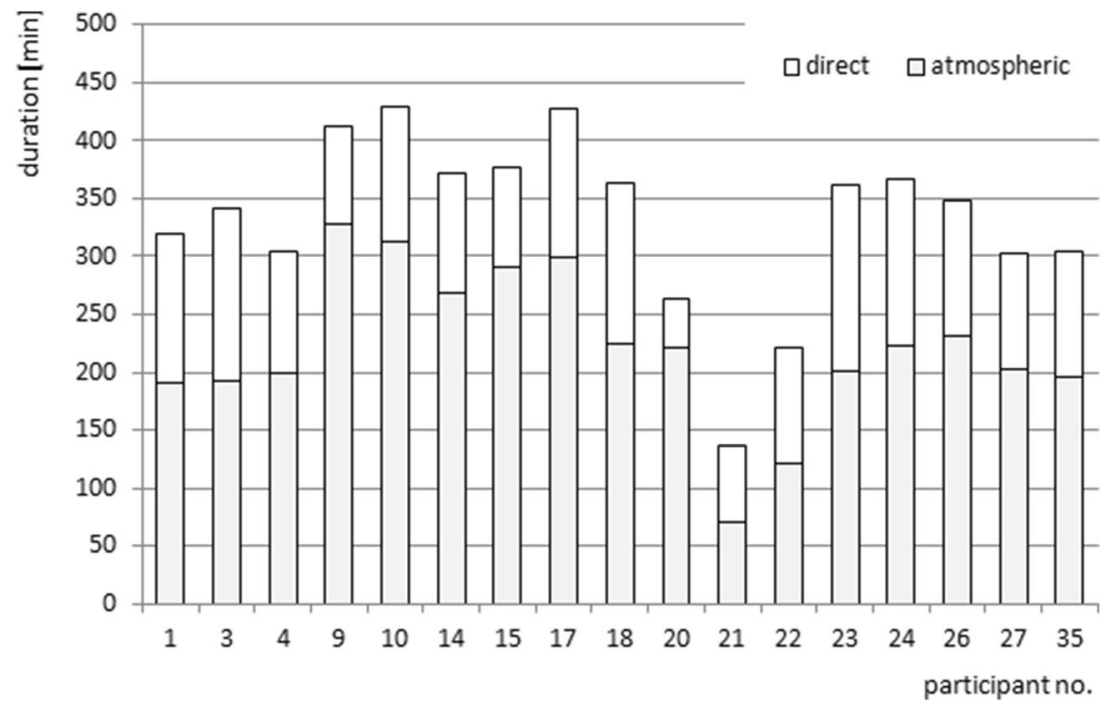


Table 2 Humor categories used by residents and Clowns

\begin{tabular}{llllllll}
\hline $\begin{array}{l}\text { Humor } \\
\text { category author }\end{array}$ & Verbal & Non-verbal & $\begin{array}{l}\text { Funny } \\
\text { accessories }\end{array}$ & $\begin{array}{l}\text { As-if- } \\
\text { game }\end{array}$ & $\begin{array}{l}\text { Sexual } \\
\text { humor }\end{array}$ & Laughter & Music \\
\hline Residents & $53 \%$ & $23 \%$ & $13 \%$ & $9 \%$ & $1 \%$ & $1 \%$ & - \\
Clowns & $31 \%$ & $28 \%$ & $13 \%$ & $16 \%$ & $1 \%$ & $4 \%$ & $7 \%$ \\
\hline
\end{tabular}

(coded as make-believe) as well as made good use of accessories. Others, however, did not contribute much, although they seemed to have the necessary skills. E.g., participants 1, 4 and 27 were attested the necessary cognitive, verbal and physical prerequisites for broader engagement by the MMST, staff, and observers, but obviously could not or did not want to participate actively according to their skills. E.g., participant 27 was downright enthusiastic about the intervention and voiced her appreciation frequently, but mainly contented herself with enjoying the performance.

Figure 5 shows the frequency of positive responses (i.e., appreciation) of the EWD towards the humor productions of their peers. Again, large individual differences were observed. E.g., participant 23 was especially successful with her humor. Her first ,humor-hit "was observed during the first session. Not only did she score best in the number of contributions and number of positive feedback, but also showed the greatest reduction in challenging behavior and the increase in quality of life (Baumgartner 2016).

\section{Do Humorous Interactions Between EWD and Clinic Clowns Lead to Observable Changes in Mood, Atmosphere, and Positive Emotions?}

As already pointed out in the previous section, whenever EWDs responded to humor events, these observed humor responses were mostly positive and can be interpreted as indicators of positive emotions (e.g., smiling, laughing, enthusiasm). Most successful humor contributions were generated in a cheerful, and playful atmosphere or triggered by conversation
(Fig. 6). Clowns also frequently used residents' mood of anticipation to crack a joke.

When analyzing the musical contributions, however, only a small number of humor contributions resulted from songs (5\%). Tracks for registering noteworthy incidents initially were established without a specific purpose but turned out to be very helpful for detecting disturbances as well as positive reactions like applause $(n=38)$, praise $(n=20)$ or thanks $(n=$ $26)$. Residents voiced regrets five times when the clown visit ended and hoped for the Clowns to come again.

The Clowns' responses to residents' authorship were interpreted as a major source that contributed to the atmosphere. Each humor contribution was answered by at least one of the two Clowns. Figure 7 shows that the majority was answered with either laughter or picking up on the joke. Although the two Clowns responded quite similarly in terms of most response categories, Fig. 7 also shows differences in the Clowns' response behavior regarding "acknowledgement", "picking up" and "volitional laughter".

Significant Topics Figure 8 shows that appearance (i.e., fashion and style) was a popular topic as well as knowledge on social behavior, e.g., etiquette, and wisdom. Whenever possible, participants readily volunteered their knowledge and advice. Another significant but possibly neglected topic of interest in a nursing home environment were romantic relationships. Asif-games sometimes carried out with puppets, seemed a good technique to encourage participants to voicing their wishes.

These topics, however, were also a potential source of perceived incompetence, e.g., when participants realized they did
Fig. 3 Grouped participants' responses

\begin{tabular}{|ll|}
\hline Response & Indicator values \\
\hline passive & - no_response \\
& - acknowledgement \\
& - sleeping \\
\hline typical response & - smiling \\
& - laughter \\
& - enthusiasm \\
\hline positive & - liking \\
& - picking_up \\
\hline negative & - shyness \\
& - ambivalence \\
& - disconcertment \\
& - aversion \\
\hline
\end{tabular}

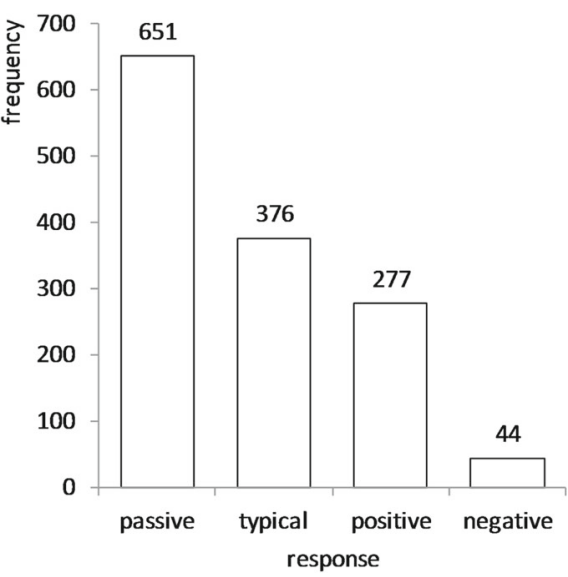


Fig. 4 Authorship by participant and humor category

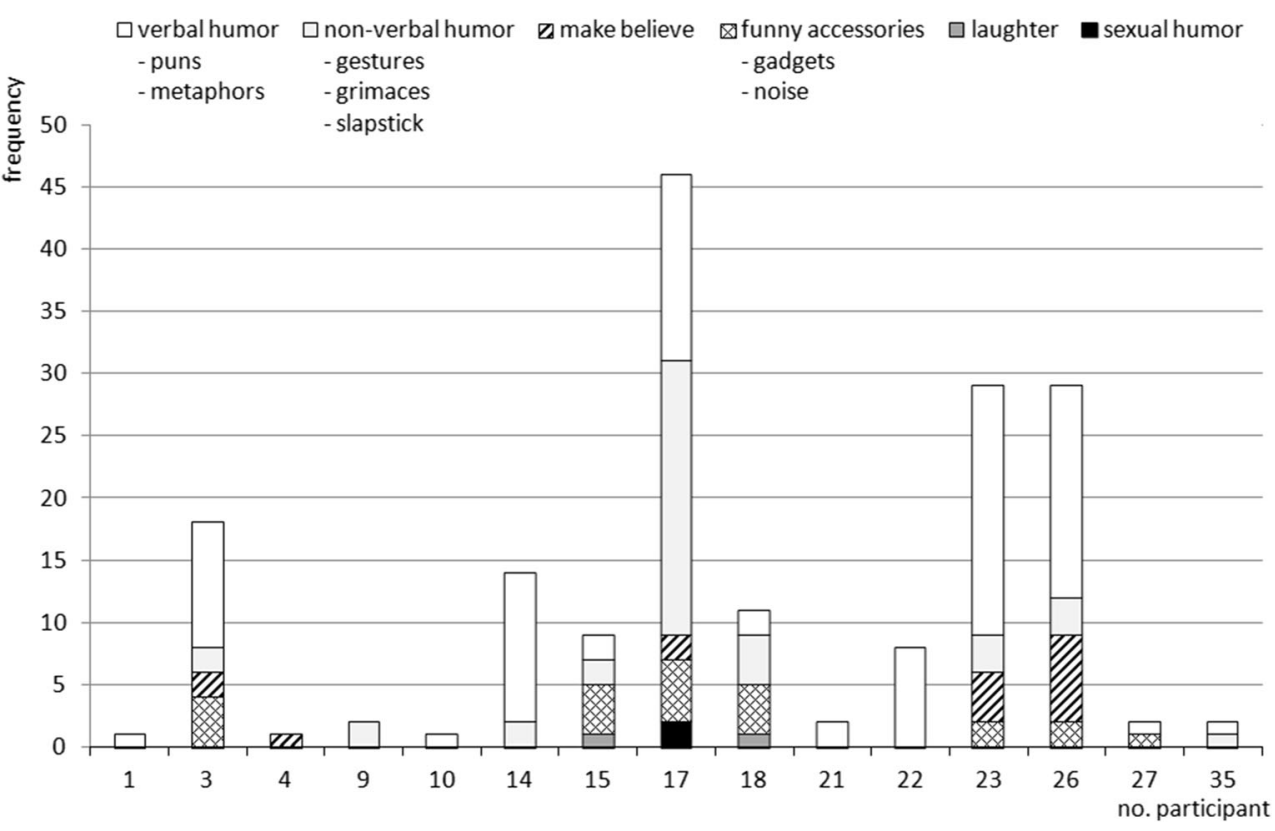

not know certain facts or could not perform a task they wished to demonstrate. This holds especially true for health issues where residents voiced their poor health and physical inabilities. Although such situations otherwise were rare, a possible negative impact should be considered in addressing specific topics.

\section{Discussion}

This study set out to develop and initially validate a behavioral observation and annotation system for humor interaction with the elderly with dementia (ANHIDE) in a sample of 17 German dementia care unit residents that were visited by
Clinic Clowns. The different categories of the ANHIDE reached a substantial inter-coder agreement and especially targeted resources and competencies that are associated with understanding and producing humor as well as contextual information. The observation of the interactions between the EWD and the Clinic Clowns with the ANHIDE provided preliminary answers regarding our two research questions that were formulated to guide the initial validation process of our newly developed instrument.

Concerning our first research question focusing on humor reception, understanding, and participation, we have observed behaviors that clearly indicate active and passive humor competencies in most of the participants of our study. Most of

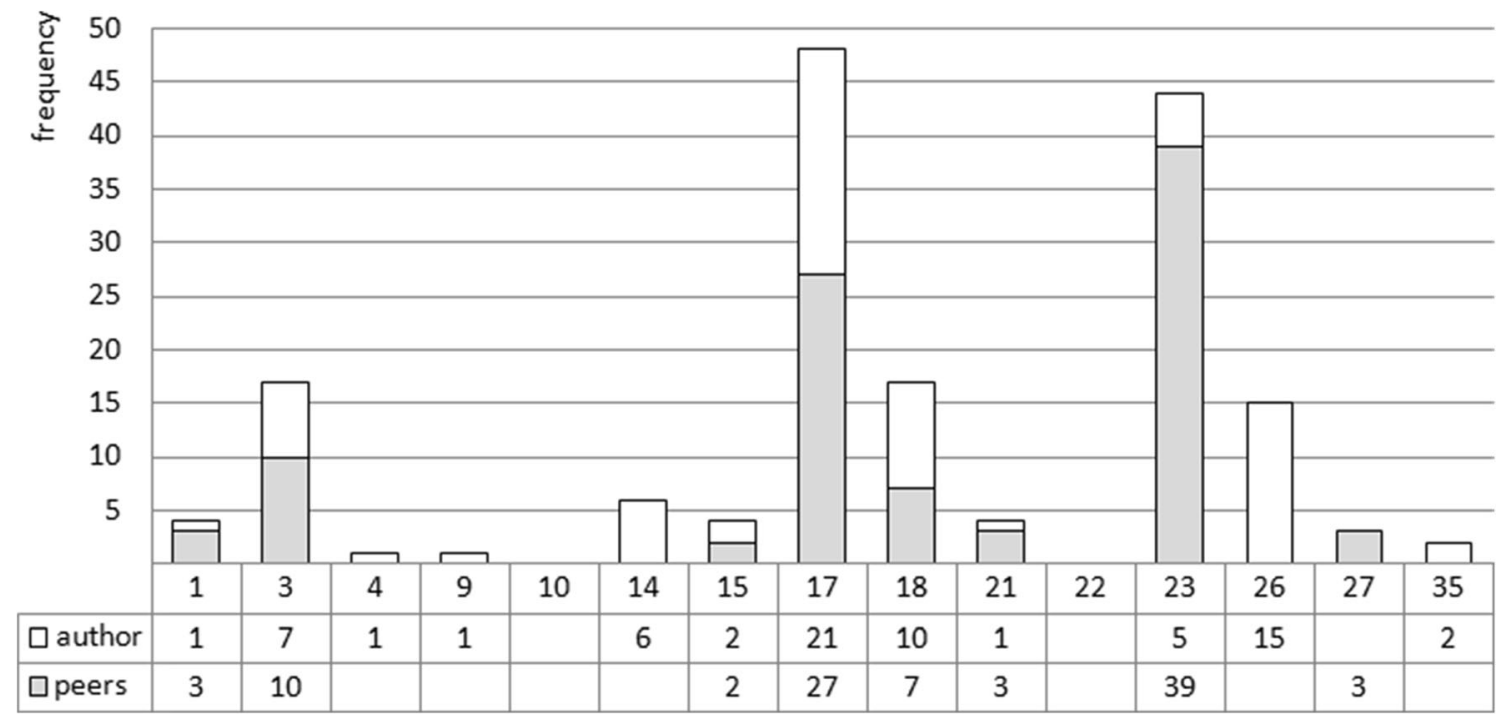

Fig. 5 Residents' positive responses to participants' humor contributions 
Fig. 6 Humor contributions and prevailing atmosphere

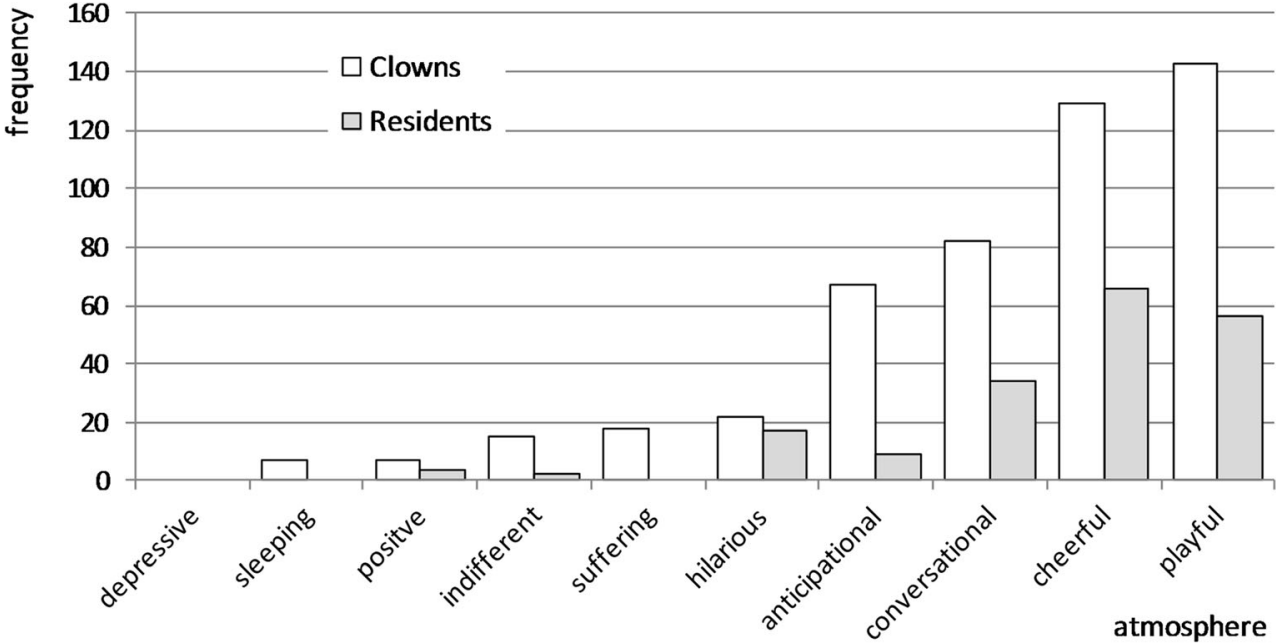

them readily engaged in humorous interaction, were able to perceive, appreciate, and produce humor and contributed about one-third of the registered humor events. Participants with mild or moderate dementia seemed to respond best. The required abilities, however, seem to remain accessible and experienceable even in advanced stages of dementia, when a wide range of other capabilities is already lost. Statements from the nursing staff, who are familiar with the resident's everyday behaviors and moods, suggest that all participants reacted positively (Baumgartner 2016, p. 121, 122). As the abilities to understand, respond, and contribute humor especially in persons with severe dementia are even more restricted, and expressions might be more subtle, concepts for addressing and observing this target group should be paid more attention to in further research.

Our second research question asked whether the humorous interactions between the EWD and the Clinic Clowns were associated with changes in mood, atmosphere, and positive emotions. When participants could be reached, $89 \%$ of the humor contributions were answered positively with laughter, smiling, or other ways of expressing appreciation. Some residents further emphasized their liking by applauding and praising the Clowns. Although negative responses were rare, they deserve further investigation, e.g., the Clowns might unintentionally violate certain norms specific for the generation most of the participants belong to.

A narrowing attention span due to dementia adds to possible declines in attentional control of the aging brain (Milham et al. 2002) and make attracting and keeping attention a major (and often underestimated) challenge for any intervention and interaction with persons with dementia (Kolanowski et al. 2012a, b). Besides, the ability to pay attention in nursing home residents seems related to positive mood (Kolanowski et al. 2012b). The clinic clown intervention proved quite successful
Fig. 7 Clown's response to participants' humor contributions

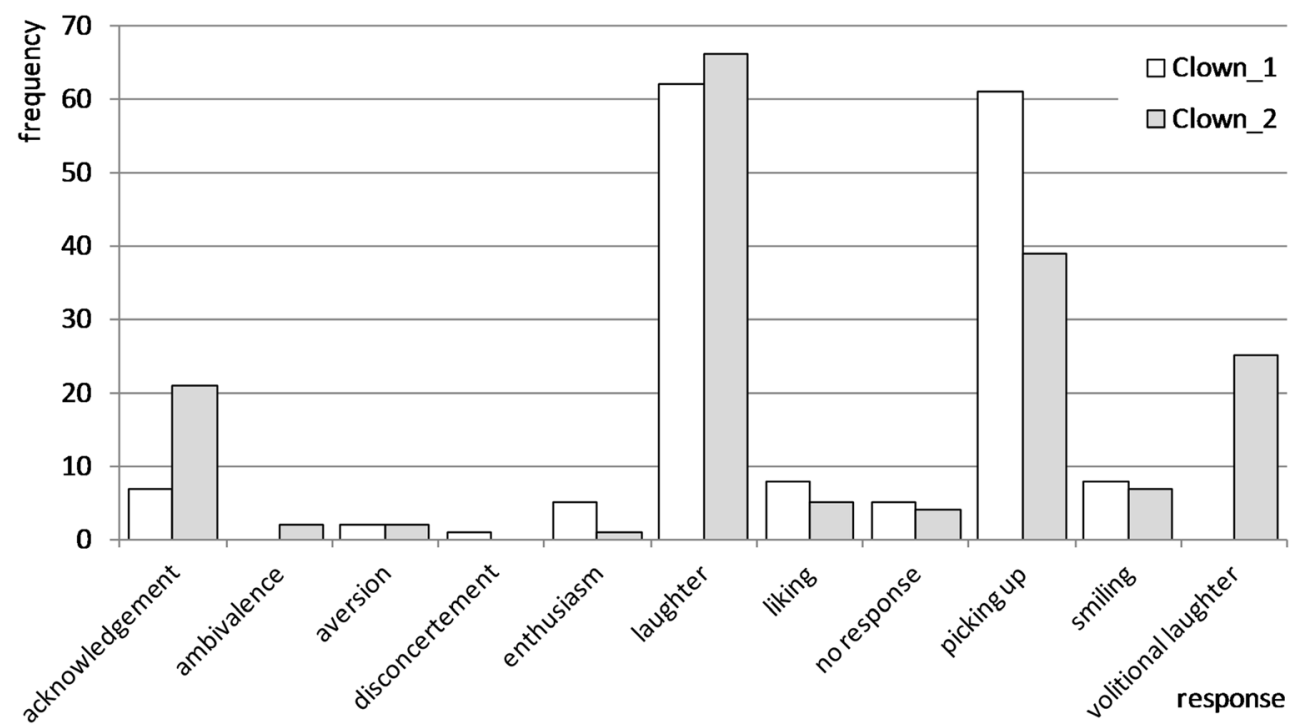




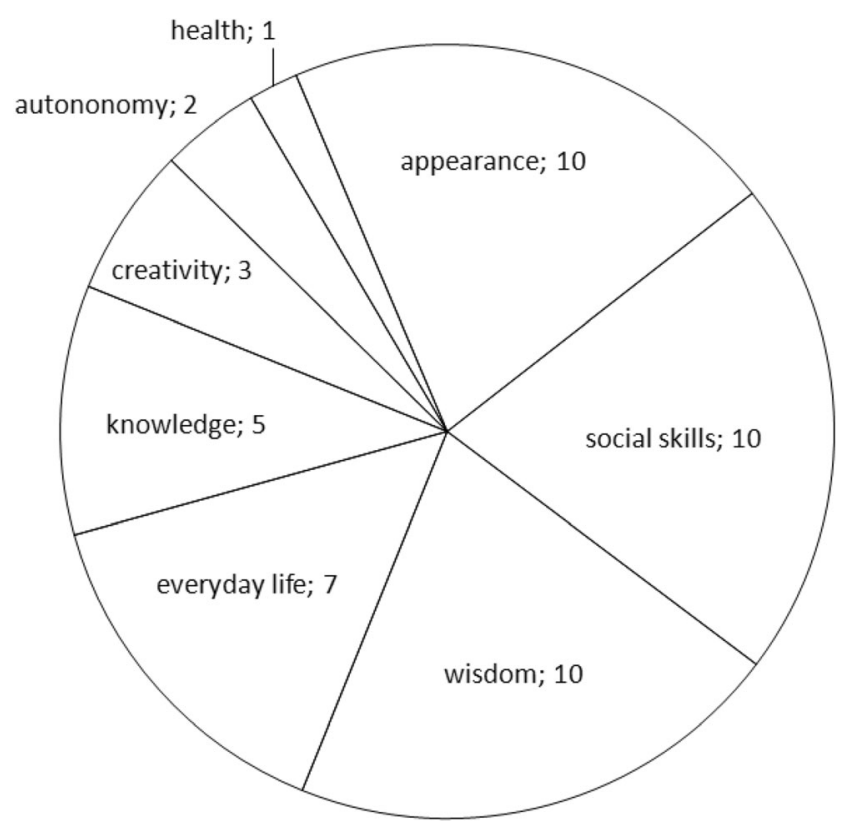

Fig. 8 Number of competencies expressed in conversation

in this respect when for two-thirds of the recorded intervention time the prevailing atmosphere was registered as conversational (24\%), playful (19\%) or positive/cheerful (22\%), especially when considering that for another $17 \%$ of the time residents kept in a state of anticipation. It is important to emphasize that aggressive humor was never directed against participants but used by the Clowns to ridicule each other or make fun of other objects only. The considerable frequency of participants' humor productions (i.e., $28 \%$ of all humor productions) attests not only a reasonable command of humor creation skills but also the willingness to employ these abilities. Most humor contributions were also accompanied by a positive reaction of the authors themselves. This might indicate the perception of successful authorship, an awareness of humor competence, or even an encouragement for the audience to join in. Dementia triggered continuous loss to perform activities of daily living (so-called ADL) increases unwanted dependency on outside help (Moyle et al. 2015). We assume that EWD might have experienced competence in terms of Ryan and Deci's Self Determination Theory (Deci and Ryan 1985, 2000; Deci 2013) whenever they succeeded in participating in humorous and playful interactions. This experience might help to compensate losses in other (e.g., daily) life episodes (Milyavskaya et al. 2013).

Also, further possible competencies like counseling, prosocial behavior, or wisdom that are often unused in a nursing home environment might be triggered. Participants picked up topics and shared their expertise either in discussion or by demonstration during the interactions with the Clinic Clowns. A combination of stylistic means usually resulted in a better comprehension and higher appreciation. Observational data of applied humor techniques showed a high readiness and ability of the EWD to engage in make-believe scenes but also a need for fostering nonverbal means of expressing humor. Makebelieve or explicit doing as-if is the central mechanism of the histrionic self-presentation style (Renner et al. 2008; Renner and Heydasch 2010; Renner and Manthey 2018). This style should also be considered in future studies investigating humorous communication with EWD as a possible personality trait that facilitates humorous interactions. Further research on these topics might result in dementia specific guidelines and training manuals. Our data also indicate substantial individual differences in humor perception and production that might be explained with such personality traits like the histrionic self-presentation style.

Data regarding significant topics like fashion, social skills, and health issues must be interpreted with caution, however, as numbers were small and the analysis of observed (nonhumorous) competencies was not a main focus of the study. Information on this behalf was gathered to encourage further investigation only. Also, whenever EWD were able to make fun of their inabilities and health issues, this might be interpreted as a means of coping with such adversities.

Environmental issues and particular needs of EWD (e.g., suitable ways of addressing, course and flow of interaction) should be paid more attention to avoid failed humor and adverse effects. In addition to the annotation with the ANHIDE and based on the grounded theory approach, the first author has also documented interactions and sequences that seemed significant to her for a holistic understanding (Baumgartner 2016). Several conditions for failed humor turned out, e.g., when Clowns sometimes came up with intellectual wordplay - possibly not even meant for the participants, but a little self-entertainment on the side -, or when the Clowns accidentally acted simultaneously, and participants were uncertain which action to follow. When the interaction was disturbed by noise or the staff serving drinks or food, the participants' attention was lost. These conditions seemed to cause puzzlement (Suls 1972), mental overload, failure to amuse, and possibly led to perceived incompetence. This might be mainly due to cognitive restraints and a limited attention span in the EWD (Kolanowski et al. 2012a, b).

Based on the documentation of significant interactions and sequences, we would like to suggest the following recommendations for the interactions between EWD and Clinic Clowns: Well-structured contributions and combined use of different stylistic means (e.g., illustrating a pun with matching slapstick) seem most likely to be successful. Long and complex verbal sequences, unstructured pauses, and distraction (e.g., environmental noise, serving drinks or meals) should be avoided. Furthermore, group settings might be sensible for persons with mild dementia only due to their better cognitive abilities compared to persons in later stages of the illness. Progression in dementia might have an impact on humor 
production skills, and indeed, in our study, productive EWD were persons with mild or moderate dementia only.

Overall, we found a high readiness of the EWD to contribute to the humorous interaction. Participants' active contribution might be further encouraged throughout the intervention period, and humor might be fostered as a behavioral competence. As some participants were even able to make fun of their health problems, e.g., joking about their declining fitness and "useless bones", humor might also be a suitable coping tool for EWD and should be promoted. Furthermore, our results demonstrate the necessity of behavioral observation in addition to output-oriented staff assessment of challenging behavior and quality of life.

\section{Limitations}

The resulting behavioral observation system benefited largely from the recorded video material but is - at the same time limited by the material at hand. Since this is the first study that used the ANHIDE, a replication of our results in a similar setting is mandatory. Besides, the inter-coder agreement suggests that coders had difficulties in differentiating between some categories, e.g., the second rater coded none of the scenes as an "as-if"-play (make-believe) but instead concentrated on the technique and devices employed. Due to restrictions of the ANVILC annotation software, it was not possible to assign multiple values to the same observation. This was a shortcoming, especially concerning our impression that a combination of stylistic means, e.g., when a pun was accompanied by slapstick, might considerably improve positive response as well as interaction and joint attention. For other problems, workarounds were easily found, e.g., by grouping observed behaviors and indicator values when redundancies emerged. These problems might be eliminated in an advanced version of the ANHIDE, allowing for multiple choice annotations. Furthermore, the ANHIDE could be refined in other respects, e.g., to facilitate registration, we coded only one single, namely the salient humor response. This sometimes led to the exclusion of less pronounced reactions, e.g., we registered "laughter" only when both "smiling", and "laughter" occurred. Since laughter and smiling certainly have different qualities, they should be separately coded in a refined version of the ANHIDE. The small number of participants in our study is also a limitation. It is clearly a challenge to recruit large samples in the field of nursing home residents with dementia, and a multi-center study would be a possible option for future studies.

\section{Conclusion}

This study focused on humor perception, appreciation, and production as resources of elderly nursing home residents with dementia. In doing so, we have developed the behavioral observation and annotation system for humor interaction with the elderly with dementia (ANHIDE) that turned out to be a valuable and reasonably reliable tool for registering behavioral indicators of humor competencies during the interaction between the elderly with dementia (EWD) and Clinic Clowns. Despite the limitations of our study, it suggests that humor interventions may be helpful for persons with dementia on a far larger scale than has been considered so far. As the experience of being able to perceive and even produce humor might compensate failure in other life episodes and hence contribute to the quality of life, a focus on methods that aim at fostering humor in EWD seems especially promising. These might be a humor training tailored for EWD, coaching of caring relatives, or staff as well as purposeful employment of Clinic Clowns. Our observations concerning competencies and skills as well as hindrances and adverse effects might also encourage further studies that aim at a better understanding of the benefits of humor for a clientele with dementia and how to smoothly weave it into their daily nursing home routine.

\section{Compliance with Ethical Standards}

Ethical Approval All procedures performed in studies involving human participants were in accordance with the ethical standards of the institutional and/or national research committee and with the 1964 Helsinki declaration and its later amendments or comparable ethical standards.

Informed Consent Informed consent was obtained from all individual participants included in the study.

Conflict of Interest The authors declare that they have no conflict of interest.

Open Access This article is distributed under the terms of the Creative Commons Attribution 4.0 International License (http:// creativecommons.org/licenses/by/4.0/), which permits unrestricted use, distribution, and reproduction in any medium, provided you give appropriate credit to the original author(s) and the source, provide a link to the Creative Commons license, and indicate if changes were made.

\section{References}

Bär, M., Kruse, A., \& Re, S. (2003). Emotional bedeutsame Situationen im Alltag demenzkranker Heimbewohner. Zeitschrift für Gerontologie und Geriatrie (Zeitschrift für Gerontologie und Geriatrie), 36(6), 454 462. https://doi.org/10.1007/s00391-003-0191-0.

Bär, M., Böggemann, M., Kaspar, R., Re, S., Berendonk, C., Seidl, U., Kruse, A., \& Schröder, J. (2006). Demenzkranke Menschen in individuell bedeutsamen Alltagssituationen. Zeitschrift für Gerontologie und Geriatrie, 39(3), 173-182. https://doi.org/10. 1007/s00391-006-0384-4.

Baumgartner, G. (2016). Selbstaktualisierung und Steigerung der Lebensqualität demenziell veränderter Menschen durch Humorintervention. Eine Studie mit professionellen Klinikclowns und demenziell veränderten Menschen in einer vollstationären 
Pflegeeinrichtung. Available online at http://athene-forschung. unibw.de/node?id=114727. Accessed 05.11.2019.

Bischofberger, I. (2007). Humor - das "gewisse Etwas" in der Pflegebeziehung. In R. D. Hirsch (Ed.), Heiterkeit und Humor im Alter. Nachdr. Bonn; Hamburg; Kassel (Schriftenreihe der Deutschen Gesellschaft für Gerontopsychiatrie und psychotherapie, 2) (pp. 163-180).

Coulter, J. (1979). The social construction of mind. Studies in ethnomethodology and linguistic philosophy. London: Macmillan.

Cummings, J. L. (2009). Neuropsychiatric Inventory Nursing Home Version (NPI-NH). Comprehensive assessment of psychopathology in patients with dementia residing in nursing homes. http://www. dementiamanagementstrategy.com/File.axd?id=c9f7405f-35964f5f-9f8d-f322e5188678. Accessed 5.11.2019.

Deci, E. L. (2013). Opening remarks from the 5th conference on selfdetermination theory. Available online at https://www.youtube.com/ watch?v=C4E10e8zIkw. Accessed 05.11.2019.

Deci, E. L., \& Ryan, R. M. (1985). Intrinsic motivation and selfdetermination in human behavior. New York: Plenum Press (Perspectives in social psychology).

Deci, E. L., \& Ryan, R. M. (2000). The "what" and "why" of goal pursuits. Human needs and the self-determination of behavior. Psychological Inquiry, 11(4), 227-268. https://doi.org/10.1207/ S15327965PLI1104 01.

Dichter, M. N., Halek, M. \& Bartholomeyczik, S. (2014a). Lebensqualitätsinstrumente. Zuverlässigkeit von standardisierten Lebensqualitätsinstrumenten für Menschen mit Demenz in der stationären Altenpflege. Schwerpunkt verstehende Diagnostik bei Menschen mit Demenz, 279-286.

Dichter, M. N., Schwab, C. G. G., Meyer, G., Bartholomeyczik, S., Dortmann, O., \& Halek, M. (2014b). Measuring the quality of life in mild to very severe dementia: Testing the inter-rater and intra-rater reliability of the German version of the QUALIDEM. International psychogeriatrics / IPA, 26(5), 825-836. https://doi.org/10.1017/ S1041610214000052.

Dooley, J., Bailey, C., \& McCabe, R. (2015). Communication in healthcare interactions in dementia: A systematic review of observational studies. International Psychogeriatrics, 27(8), 1277-1300. https://doi.org/10.1017/S1041610214002890

Dunn, J., Balfour, M., Moyle, W., Cooke, M., Martin, K., Crystal, C., \& Yen, A. (2013). Playfully engaging people living with dementia. Searching for Yum Cha moments. International Journal of Play, 2(3), 174-186. https://doi.org/10.1080/21594937.2013.852052.

Ettema, T. P., Dröes, R.-M., de Lange, J., Mellenbergh, G. J., \& Ribbe, M. W. (2007). QUALIDEM: Development and evaluation of a dementia specific quality of life instrument - validation. International Journal of Geriatric Psychiatry, 22(5), 424-430. https://doi.org/10. 1002 /gps.1692.

Falkenberg, I. (2010). Entwicklung von Lachen und Humor in den verschiedenen Lebensphasen. Zeitschrift für Gerontologie und Geriatrie, 43(1), 25-30. https://doi.org/10.1007/s00391-0090085-x.

Fassnacht, G. (1995). Systematische Verhaltensbeobachtung. Eine Einführung in die Methodologie und Praxis (2. völl. neubearb. Aufl.). München: Ernst Reinhardt.

Folstein, M. F., Folstein, S. E., \& MacHugh, P. R. (2000). Mini-MentalStatus-Test. MMST. Dt. Fassung. Weinheim: Beltz (Beltz-Test).

Fry, W. F. (1994). The biology of humor. Humor - International Journal of Humor Research, 7(2), 111-126. https://doi.org/10.1515/humr. 1994.7.2.111.

Garms-Homolová, V., \& Kiki, N. (2003). Clowns im Pflegeheim? Zur Frage der Beeinflussung von Verhaltensauffälligkeiten durch die humortherapeutische Intervention. Psychomed, 15(2), 106-113.

Gironzetti, E., Pickering, L., Huang, M., Zhang, Y., Menjo, S., \& Attardo, S. (2016). Smiling synchronicity and gaze patterns in dyadic humorous conversations. Humor, 29(2). https://doi.org/10.1515/ humor-2016-0005.

Harré, R. (1991). The discursive production of selves. Theory and Psychology, 1(1), 51-63. https://doi.org/10.1177/ 0959354391011004.

Hawkins, D. B., \& Graff-Radford, N. R. (2007). The ability to pun may be retained in Alzheimer disease. Neurocase, 13(1), 50-54. https:// doi.org/10.1080/13554790701254673.

Hay, J. (2001). The pragmatics of humor support. Humor - International Journal of Humor Research, 14(1). https://doi.org/10.1515/humr. 14.1.55.

Kolanowski, A. M., Fick, D. M., Yevchak, A. M., Hill, N. L., Mulhall, P. M., \& McDowell, J. A. (2012a). Pay attention! The critical importance of assessing attention in older adults with dementia. In J gerontology, 38(11), 23-27. https://doi.org/10.3928/0098913420121003-05.

Kolanowski, A., Bossen, A., Hill, N., Guzman-Velez, E., \& Litaker, M. (2012b). Factors associated with sustained attention during an activity intervention in persons with dementia. Dementia and Geriatric Cognitive Disorders, 33(4), 233-239. https://doi.org/10.1159/ 000338604.

Kontos, P., Miller, K.-L., Mitchell, G. J., \& Stirling-Twist, J. (2015). Presence redefined: The reciprocal nature of engagement between elder-clowns and persons with dementia. Dementia (London, England)., 16, 46-66. https://doi.org/10.1177/1471301215580895.

Krappmann, L., \& Oswald, H. (1995). Unsichtbar durch Sichtbarkeit. Der teilnehmende Beobachter im Klassenzimmer. In I. Behnken \& $O$. Jaumann (Hrsg.), Kindheit und Schule. Kinderleben im Blick von Grundschulpädagogik und Kindheitsforschung (Kindheiten, 3950). Weinheim: Juventa.

Kruse, A. (2005). Selbstständigkeit, bewusst angenommene Abhängigkeit, Selbstverantwortung und Mitverantwortung als zentrale Kategorien einer ethischen Betrachtung des Alters. Zeitschrift für Gerontologie und Geriatrie, 38(4), 273-287. https:// doi.org/10.1007/s00391-005-0323-9.

Kuiper, N. A., Kirsh, G. A., \& Leite, C. (2010). Reactions to humorous comments and implicit theories of humor styles. EJOP, 6(3), 236266. https://doi.org/10.5964/ejop.v6i3.215.

Linge-Dahl, L. M., Heintz, S., Ruch, W., \& Radbruch, L. (2018). Humor assessment and interventions in palliative care: A systematic review. Frontiers in Psychology, 9, 890. https://doi.org/10.3389/fpsyg.2018. 00890.

Low, L.-F., Brodaty, H., Goodenough, B., Spitzer, P., Bell, J.-P., Fleming, R., et al. (2013). The Sydney multisite intervention of LaughterBosses and ElderClowns (SMILE) study: Cluster randomised trial of humour therapy in nursing homes. BMJ Open, 3(1), e002072. https://doi.org/10.1136/bmjopen-2012-002072.

Martin, R. (2003). Sense of humor. In S. J. Lopez \& C. R. Snyder (Eds.), Positive psychological assessment. A handbook of models and measures. 1st ed (pp. 313-326). Washington, DC: American Psychological Association.

Martin, R. A., Puhlik-Doris, P., Larsen, G., Gray, J., \& Weir, K. (2003). Individual differences in uses of humor and their relation to psychological well-being: Development of a randomised Styleshumourionnaire. Journal of Research in Personality, 37(1), 48-75. https://doi.org/10.1016/S0092-6566(02)00534-2.

Milham, M. P., Erickson, K. I., Banich, M. T., Kramer, A. F., Webb, A., Wszalek, T., \& Cohen, N. J. (2002). Attentional control in the aging brain. Insights from an fMRI study of the Stroop task. Brain and Cognition, 49(3), 277-296. https://doi.org/10.1006/brcg.2001.1501.

Milyavskaya, M., Philippe, F. L., \& Koestner, R. (2013). Psychological need satisfaction across levels of experience. Their organization and contribution to general well-being. Journal of Research in Personality, 47(1), 41-51. https://doi.org/10.1016/j.jrp.2012.10.013.

Moyle, W., Fetherstonhaugh, D., Greben, M., \& Beattie, E. (2015). Influencers on quality of life as reported by people living with 
dementia in long-term care: A descriptive exploratory approach. BMC Geriatrics, 15, 50. https://doi.org/10.1186/s12877-015-0050$\mathrm{z}$.

Proyer, R. T., Ruch, W., \& Müller, L. (2010). Sense of humor among the elderly. Zeitschrift für Gerontologie und Geriatrie, 43(1), 19-24. https://doi.org/10.1007/s00391-009-0082-0.

Re, S. (2003). Erleben und Ausdruck von Emotionen bei schwerer Demenz. Hamburg: Kovač.

Renner, K. H., \& Heydasch, T. (2010). Performing humor: On the relations between self-presentation styles, Gelotophobia, Gelotophilia, and Katagelasticism. Psychological Test and Assessment Modeling, 52, 171-190

Renner, K.-H., \& Manthey, L. (2018). Relations of dispositions toward ridicule and histrionic self-presentation with quantitative and qualitative humor creation abilities. Frontiers in Psychology, 9, 78. https://doi.org/10.3389/fpsyg.2018.00078.

Renner, K.-H., Enz, S., Friedel, H., Merzbacher, G., \& Laux, L. (2008). Doing as if: The histrionic self-presentation style. Journal of Research in Personality, 42, 1303-1322. https://doi.org/10.1016/j. jrp.2008.04.005.

Ruch, W. (1983). Humor-test 3 WD. Form A, B and K. unpublished manuscript. University of Düsseldorf, Department of Psychology.

Ruch, W., \& Köhler, G. (2007). A temperament approach to humor. In W. Ruch (Ed.), The sense of humor. Explorations of a personality characteristic. Berlin; New York: Mouton de Gruyter (Humor research, 3).

Ruch, W., Proyer, R. T., \& Weber, M. (2010). Humor as a character strength among the elderly. Theoretical considerations. Zeitschrift für Gerontologie und Geriatrie, 43(1), 8-12. https://doi.org/10. 1007/s00391-009-0080-2.

Stevens, J. (2012). Stand up for dementia. Performance, improvisation and stand up comedy as therapy for people with dementia; a qualitative study. Dementia, 11(1), 61-73. https://doi.org/10.1177/ 1471301211418160.

Suls, J. M. (1972). A two-stage model for the appreciation of jokes and cartoons: An information-processing analysis. In The psychology of humor (pp. 81-100). Elsevier.

Thaler, A., Posen, J., Giladi, N., Manor, Y., Mayanz, C., Mirelman, A., \& Gurevich, T. (2012). Appreciation of humor is decreased among patients with Parkinson's disease. Parkinsonism \& Related Disorders, 18(2), 144-148. https://doi.org/10.1016/j.parkreldis. 2011.09.004.

Publisher's Note Springer Nature remains neutral with regard to jurisdictional claims in published maps and institutional affiliations. 